University of Wollongong

Research Online

Faculty of Social Sciences - Papers (Archive) Faculty of Arts, Social Sciences \& Humanities

2019

Increased Beta Activity Links to Impaired Emotional Control in ADHD Adults With High IQ

Hui Li

Peking University

Qihua Zhao

Peking University

Fang Huang

Peking University

Qingjiu Cao

Peking University

Stuart J. Johnstone

University of Wollongong, sjohnsto@uow.edu.au

See next page for additional authors

Follow this and additional works at: https://ro.uow.edu.au/sspapers

Part of the Education Commons, and the Social and Behavioral Sciences Commons

Research Online is the open access institutional repository for the University of Wollongong. For further information contact the UOW Library: research-pubs@uow.edu.au 


\title{
Increased Beta Activity Links to Impaired Emotional Control in ADHD Adults With High IQ
}

\begin{abstract}
Objective: The present study investigated the neuropathology of everyday-life executive function (EF) deficits in adults with ADHD with high IQ. Method: Forty adults with ADHD with an IQ $\geq 120$ and 40 controls were recruited. Ecological EFs were measured, and eyes-closed Electroencephalograph (EEG) signals were recorded during a resting-state condition; EEG power and correlations with impaired EFs were analyzed. Results: Compared with controls, the ADHD group showed higher scores on all clusters of EF. The ADHD group showed globally increased theta, globally decreased alpha, and increased central beta activity. In the ADHD group, central beta power was significantly related to emotional control ratings, while no such correlation was evident in the control group. Conclusion: The results suggest that restingstate beta activity might be involved in the neuropathology of emotional control in adults with ADHD with high IQ.
\end{abstract}

\section{Keywords}

emotional, impaired, iq, high, adults, links, adhd, activity, control, increased, beta

\section{Disciplines}

Education | Social and Behavioral Sciences

\section{Publication Details}

Li, H., Zhao, Q., Huang, F., Cao, Q., Johnstone, S. J., Wang, Y., Wang, C. \& Sun, L. (2019). Increased Beta Activity Links to Impaired Emotional Control in ADHD Adults With High IQ. Journal of Attention Disorders, 23 (7), 754-764.

\section{Authors}

Hui Li, Qihua Zhao, Fang Huang, Qingjiu Cao, Stuart J. Johnstone, Yufeng Wang, Changming Wang, and Li Sun 


\section{Increased beta activity links to impaired emotional control in AD/HD adults with high IQ}

Hui Li ${ }^{\mathrm{a}, \mathrm{b}, \mathrm{c}}$, Changming Wang ${ }^{\mathrm{d}}$, Qihua Zhao ${ }^{\mathrm{a}, \mathrm{b}, \mathrm{c}}$, Fang Huang ${ }^{\mathrm{a}, \mathrm{b}, \mathrm{c}}$, Qingjiu Cao ${ }^{\mathrm{a}, \mathrm{b}, \mathrm{c}}$, Qiujin Qian ${ }^{\mathrm{a}, \mathrm{b}, \mathrm{c}}$, Stuart Johnstone ${ }^{\mathrm{e}}$, Yufeng Wang ${ }^{\mathrm{a}, \mathrm{b}, \mathrm{c}}$, Li Sun $^{\mathrm{a}, \mathrm{b}, \mathrm{c}, *}$

\footnotetext{
${ }^{\text {a }}$ Peking University Sixth Hospital/Institute of Mental Health, Beijing, 100191, China;

${ }^{b}$ National Clinical Research Center for Mental Disorders \& Key Laboratory of Mental Health, Ministry of Health (PekingUniversity), Beijing, 100191, China;

${ }^{c}$ Key Laboratory of Mental Health, Ministry of Health, Peking University, Beijing, 100191, China;

${ }^{\mathrm{d} B e i j i n g}$ Anding Hospital of Capital Medical University, Beijing, 100088, China;

${ }^{\mathrm{e}}$ Brain and Behaviour Research Institute, School of Psychology, University of Wollongong, Wollongong, Australia.
}

\section{*Address correspondence and reprint request to:}

Li Sun, PhD, Institute of Mental Health, Peking University

Email: sunlioh@bjmu.edu.cn

Acknowledgement: This work was supported by the National Natural Sciences Foundation of China (81371496), the National Basic Research Program of China (973 program 2014CB846104), the National Key Technology R\&D Program (2015BAI13B01), and the National Natural Sciences Foundation of China (81471382, 81641163).

\section{Conflict of Interest Statement:}

None of the authors have potential conflicts of interest to be disclosed. 


\begin{abstract}
Objective: The present study was to investigate the ecological executive function (EF) impairments and their correlations with resting-state EEG in AD/HD adults with high IQ and to illustrate the neuropathology of individual everyday-life EF deficits in $\mathrm{AD} / \mathrm{HD}$.

Methods: Forty $\mathrm{AD} / \mathrm{HD}$ adults with $\mathrm{IQ} \geq 120$ and 40 controls were recruited, and the Behavior Rating Inventory of Executive Function, Adult Version (BRIEF-A) were used to investigate the ecological EF. The eyes-closed EEG signals were recorded during a resting state condition, and the relative power in delta, theta, alpha, and beta bands were measured. Further, the correlations between impaired EFs and EEG abnormalities were analyzed.

Results: The AD/HD group showed higher scores in all clusters of EF in BRIEF-A. Compared to controls, the AD/HD group showed globally increased theta, globally decreased alpha, and increased central beta activities. In AD/HD group, the central relative beta power significantly related to the emotional control ratings, while no such correlation showed in control group.
\end{abstract}

Conclusions: The results suggest that the resting-state beta activity might involve in neuropathology of emotional control in AD/HD adults with high IQ.

Significance: This is the first study to examine the correlations between ecological executive functions and resting-state EEG in AD/HD adults with high IQ.

\title{
Keywords
}

AD/HD; high IQ; EEG; executive function; BRIEF 


\section{Highlights}

- The AD/HD adults with high IQ suffered significant executive function impairments in daily life.

- The high IQ AD/HD individuals showed aberrant resting-state EEG pattern.

- The enhancement of central beta activity links to emotional control deficiencies in adults with AD/HD. 


\section{Introduction}

Attention-deficit/hyperactivity disorder (AD/HD) is a neuropsychiatric disorder characterised by symptoms of inattention and/or hyperactivity or impulsivity. Although $\mathrm{AD} / \mathrm{HD}$ has primarily been considered a disorder of childhood, it is now known that up to $50 \%$ of $\mathrm{AD} / \mathrm{HD}$ children continue to manifest symptoms in adulthood (Biederman et al., 2010; Lara et al., 2009). The symptoms of adults with AD/HD are different from childhood AD/HD, hyperactivityis expressed as restlessness while inattention and impulsivity tend to persist (APA, 2013). As the adults with AD/HD are increasingly recognized to suffer more impairments in psychosocial, educational, and neurocognitive functioning than healthy adults (Klassen et al., 2010), as well as more psychiatric comorbidities, such as bipolar disorderand anxiety disorder (Biederman et al., 2004), there is a growing interest in the field of adult $\mathrm{AD} / \mathrm{HD}$.

Based on the clinical practice, researchers have observed that ADHD adults with high IQ have chronic difficulties with focusing on their work, organizing the materials, and suffer procrastination and forgetfulness. Although these individuals are competent and talented, they have significant executive functions deficits to manage their abilities for daily tasks (Brown et al., 2009). Since Barkley (1997) proposed the comprehensive theory that symptoms of deficient EF might be core deficits in AD/HD (Barkley, 1997; Hervey et al., 2004), many studies have reported that $\mathrm{AD} / \mathrm{HD}$ individuals exhibit a wide range of deficit EFs (Boonstra et al., 2005; Salomone et al., 2016). However, these studies of EF deficiencies in adults with AD/HD involved subjects with a wide spectrum of IQ, and the characteristics of EF in ADHD adults with high IQ have received less attention in the scientific literature. We only found one study focused on the AD/HD adults with high IQ ( $\geq 120)$, reporting $\mathrm{AD} / \mathrm{HD}$ subjects exist significant $\mathrm{EF}$ impairments in standardized test of memory and cognitive abilities and self-report measures of daily life (Brown et al., 2009).

In most of these high IQ adults, $\mathrm{AD} / \mathrm{HD}$ symptoms and impairments were not recognized, evaluated and treated until they were facing increased demands for EF in high school or even university studies. Thus, understanding a specific profile of EF 
characteristics in AD/HD adults with high IQ could facilitate clinical diagnosis and treatment. Meanwhile, as these high IQ patients are excellent example to explore how general cognitive abilities (from IQ test) can be distinguished from executive function deficits in $\mathrm{AD} / \mathrm{HD}$ (Brown et al.,2009), cognitive studies among these subjects are important. However, to the date the studies focusing on these high IQ subjects with $\mathrm{AD} / \mathrm{HD}$ are rare. Thus, this study aimed to shed more light on the characteristics and underlying neural mechanism of daily EF deficits in the AD/HD adults with high IQ.

Previous neuropsychological studies generally apply various laboratory tasks to estimate the EFs among adults with AD/HD. However, the method regarding EF performance in laboratory tasks as the primary index of EF deficits has been challenged in recent years (Barkley \& Murphy, 2011). Since EF were defined as neurocognitive processes that maintain an appropriate problem-solving set toward a goal (Barkley, 1997; Willcutt et al., 2005), traditional short duration tests of EF may not be appropriate to examine EF functioning in daily life (Barkley \& Murphy, 2011). For the individuals with high IQ, it is more likely that these laboratory tasks have too low a ceiling to be sufficiently sensitive to distinguish their EF impairments. Other researchers have found that EF deficits in young adults with $\mathrm{AD} / \mathrm{HD}$ are more adequately identified by self-report and clinical interviews involving impairments of self-management in daily adaptive functioning instead of neuropsychological tests (Stavro et al., 2007). It has been suggested that using self-report ratings of EFs for neuropsychological assessments in adults with $\mathrm{AD} / \mathrm{HD}$ is perhaps more valid, considering their high ecological validity (Fuermaier et al., 2014). Therefore, ecological EF scales according to individual daily behavior might be more appropriate and effective to reflect the EF deficits for AD/HD adults. For the above reasons, self-report ratings of ecological EFs were examined in this study due to their ability to reflect everyday-life behavioural performance (e.g.ability to solve problems and achieve goals) in AD/HD adults with high IQ.

Furthermore, the resting-state EEG was used to explore the neuropathology of EF deficits in $\mathrm{AD} / \mathrm{HD}$. Because of the efficiency and non-invasive nature of obtaining high-temporal resolution brain activity data, resting-state EEG is an appropriate tool to 
investigate the neural mechanism of individual behaviour. It has been applied in the studies on $\mathrm{AD} / \mathrm{HD}$ children and adolescents for more than 30 years. The most robust findings in $\mathrm{AD} / \mathrm{HD}$ children under the resting-state conditions are increased theta activity and decreased beta activity, especially in frontocentral region (Barry et al., 2003). In recent ten years, increasing studies on the resting-state EEG have brought new evidence to identify the nature of brain activity in adult AD/HD. Bresnahan et al. (1999) firstly observed higher delta and theta activity remain in adults with AD/HD (Bresnahan et al., 2006). Most of later studies also reported the abnormalities in slow and fast wave EEG in adults with AD/HD (Clarke et al., 2008; Hermens et al., 2004; Woltering et al., 2012). These abnomal resting-state EEG indicated that the AD/HD adults have abarrent neural activities, but the relationship between EEG abnormalities and behavioural impairments is still poorly understood. Previous study investigated the correlation between BRIEF and EEG in children with $\mathrm{AD} / \mathrm{HD}$, reporting theta activity positively correlates with deficient metacognition and negatively correlates with inhibition (Ogrim et al., 2012). It is likely that the resting-state EEG abnomalities involve in the neurophysiological mechanisms of daily EF deficits in AD/HD. However, we did not find any study examining the relationship between ecological Efs and resting-state EEG abnormalities in AD/HD adults with high IQ. Only one study has related resting-state EEG indices to EFs in AD/HD adults, observing theta/beta ratio was negatively correlated to the speed of responding to choice stimuli in the Stop-Signal task (van Dongen-Boomsma et al., 2010).

In all, the purpose of our study was (1) to expand existing knowledge regarding the EF impairments in AD/HD adults with high IQ and (2) to explore the relationship between ecoligical EF deficits and resting-state EEG abnormalities. It was predicted that ecological EF impairments and aberrant EEG pattern would be present in these high-functioning individuals, and resting-state EEG abnormalities might link to daily behavioral impairments in $\mathrm{AD} / \mathrm{HD}$ adults with high IQ. 


\section{Materials and Methods}

\subsection{Participants}

Forty adults diagnosed with AD/HD (age $=25.85 \pm 5.21$ years, IQ $=128.18 \pm 5.25)$ and 40 age- and sex-matched healthy control subjects $($ age $=25.88 \pm 3.83$ years, IQ $=$ 126.35 \pm 4.96$)$ took part in this study. AD/HD subjects were recruited from the Peking University Sixth Hospital, and fulfilled a diagnosis of adult AD/HD through Conners' Adult AD/HD Diagnostic Interview based on Diagnostic and Statistical Manual of Mental Disorders, Fourth Edition (DSM-IV) (Epstein \& Johnson, 2001). Twenty-nine individuals (13 females) met the criteria for the predominantly inattentive subtype (AD/HD-I), 2 individuals (both males) met the criteria for $\mathrm{AD} / \mathrm{HD}$ of the hyperactive-impulsive subtype (AD/HD-H), and 9 individuals (4 females) met the criteria for $\mathrm{AD} / \mathrm{HD}$ of the combined subtype (AD/HD-C). All AD/HD subjects were medication naïve.Other current psychopathology was assessed with the Structured Clinical Interview for DSM-IV Axis I Disorders (SCID). There were 4 subjects with anxiety, 2 subjects with obsessive compulsive disorder, 1 subject with bipolar, 1 subject with social phobia, 1 subject with substance abuse and 6 subjects with a history of depression. Control subjects were recruited from local universities or communities, and interviewed to ensure an absence of past or current AD/HD. Subject demographics are presented in Table 1.

The inclusion criteria included: (1) age $\geq 18$; (2) no history of head trauma with loss of consciousness; (3) no history of neurological illness or other severe disease; (4) an IQ $\geq 120$ on the Full scale Wechsler Adult Intelligence Scale Revised in China (WAISRC).

This study was approved by the Research Ethics Review Board of Peking University Institute of Mental Health and all participants provided informed written consent prior to the start of the study. 
2.2 Ecological EF measures: Behavior Rating Inventory of Executive Function, Adult Version

The Behavior Rating Inventory of Executive Function, adult version (BRIEF-A) is a 75-item self-rating questionnaire of ecologiacl EF over the last 30 days (Roth et al., 2005). Subjects report how problematic a behavior has been and scores on each of the items range from 1 to 3:never ( 1 point), sometimes ( 2 points), or often (3 points). Higher scores mean more executive dysfunction. The Global Executive Composite (GEC) is an overall score, which is the sum of the Behavior Regulation Index (BRI) and Metacognition Index (MI). The BRI is composed of the Inhibit, Shift, Emotional control and Self-monitor scales, which measures the ability to maintain control over behavior, emotional responses. The MI is composed of the Initiate, Working memory, Plan/Organize, Organization of materials, and Task-monitor scales, which measures the ability to solve problems through working memory, planning, and organization (Vynorius et al., 2016). In this study, each component had been treated as a separate item to present a more detailed characteristics of individual ratings of EF impairments on different clusters.

\subsection{EEG data procedure}

The participants were seated comfortably in a dimly-lit room with a low level of environmental noise. They were instructed to stay relaxed and motionless. EEG data were recorded continuously during 6 min of a resting eyes-closed condition with a 128-channel system (HydroCel Geodesic Sensor Net, Electrical Geodesics, Inc., Eugene, OR). Within NetStation (Electrical Geodesic Inc, EGI), EEG data were collected using a 1000Hz sampling rate and digitally filtered $(0.01-100 \mathrm{~Hz})$. All the electrode impedances were kept under $50 \mathrm{k} \Omega$. Data were referenced to electrode $\mathrm{Cz}$. The on-going EEG recording was continuously monitored to ensure data quality and to control vigilance in the subjects.

In MATLAB, EEG signals were subsequently down-sampled to $250 \mathrm{~Hz}$ and transformed to the average reference. An Independent Components Analysis (ICA) decomposed the measured EEG signals into independent components and those components sensitive to eye-blinks and eye movements were then removed (Delorme \& 
Makeig, 2004). All EEG data were manually reviewed and channels containing muscle or any other non-physiological artifact were discarded. A wavelet transform was used to obtain time-frequency domain measures. For this study, nineteen channels were selected based on the international 10-20 system and EEG power was derived from the average for the delta $(1-4 \mathrm{~Hz})$, theta $(4-8 \mathrm{~Hz})$, alpha $(8-13 \mathrm{~Hz})$, and beta $(13-30 \mathrm{~Hz})$ frequency bands. The relative power of the four bands were calculated in the statistical analysis as these indices are reliable to identify EEG characteristics in participants with AD/HD (Clarke et al., 2011).

\subsection{Statistical analysis}

All analyses were performed in SPSS version 18. For the EEG data, Independent $t$-tests were carried out on the BRIEF-A scores and the Bonferroni correction has been applied $\left(p=p^{\prime * 9}\right)$. Analyses of variance were conducted separately for each frequency band in relative power with between-subjects factor of Group (AD/HD, control) and within-subjects topographic factors of Lateral (left, midline, right) and Sagittal (frontal, central, posterior). According to an established method measuring the topographic effects (Clarke et al., 2001; 2008), the following electrodes were chosen and divided into nine regions: left frontal $(\mathrm{F} 3, \mathrm{~F} 7)$, midline frontal $(\mathrm{Fz})$, right frontal $(\mathrm{F} 4, \mathrm{~F} 8)$, left central $(\mathrm{T} 3$, C3), midline central $(\mathrm{Cz})$, right central (T4, C4), left posterior (T5, P3, O1), midline posterior $(\mathrm{Pz})$ and right posterior $(\mathrm{T} 6, \mathrm{P} 4, \mathrm{O} 2)$. The EEG data for each region were calculated by averaging all electrode(s) within the area. Then planned contrasts within the Sagittal and Lateral factors were examined to compare the EEG difference of regions between two groups.

Further, Pearson's correlation analyses were applied to examine relationships between the scores of nine clusters in BRIEF-A and the EEG relative power that differed significantly between the $\mathrm{AD} / \mathrm{HD}$ and control group. The electrodes had been divided into three regions: frontal (F3, F7, Fz, F4, F8), central (T3, C3, Cz, T4, C4) and posterior (T5, $\mathrm{P} 3, \mathrm{O} 1, \mathrm{Pz}, \mathrm{T} 6, \mathrm{P} 4, \mathrm{O} 2)$ to reduce multiple comparisons. The Bonferroni correction had 
been applied in the correlation analysis for each relative power $\left(p=p^{\prime * 9}\right)$. All tests were 2-tailed and alpha was set at .05.

\section{Results}

3.1 Demographic and clinical measures

There were no significant differences between the AD/HD and control group for age estimated IQ, or sex ratio. According to the clinical measures, the AD/HD group had significantly higher scores than controls for inattention and hyperactive-impulsive behaviours (see Table 1).

Table 1. Characteristics of the AD/HD and Control group.

\begin{tabular}{ccccc}
\hline Items & AD/HD $\boldsymbol{n}=\mathbf{4 0}$ & Controls $\boldsymbol{n}=\mathbf{4 0}$ & $\boldsymbol{t} / \boldsymbol{\chi}^{2}$ & $\boldsymbol{p}$ \\
\hline Sex & $\mathrm{M} 23 ; \mathrm{F} 17$ & M 26; F 14 & 0.474 & 0.647 \\
Age (years) & $25.85 \pm 5.21$ & $25.88 \pm 3.83$ & -0.027 & 0.978 \\
IQ & $128.18 \pm 5.25$ & $126.35 \pm 4.96$ & 1.597 & 0.114 \\
AD/HD type & $29 \mathrm{I}, 2 \mathrm{H}, 9 \mathrm{C}$ & $\mathrm{n} / \mathrm{a}$ & & \\
$\begin{array}{c}\text { AD/HD symptoms } \\
\text { Inattentive }\end{array}$ & $28.58 \pm 3.59$ & $13.75 \pm 2.41$ & 21.683 & $0.000^{* * *}$ \\
$\begin{array}{c}\text { Hyperactivity } \\
\text {-impulsive } \\
\text { Total }\end{array}$ & $18.08 \pm 4.54$ & $12.88 \pm 2.84$ & 6.139 & $0.000^{* * * *}$ \\
\hline
\end{tabular}

Note: IQ: estimated full IQ of WAISRC; AD/HD: Attention-deficit/hyperactivity disorder; I = inattentive, $\mathrm{H}=$ hyperactive-impulsive, $\mathrm{C}=$ combined; $\chi^{2}=$ chi-square test. $* * * p<0.001$ 
As displayed in Table 2, all EF scales showed significantly higher scores in the AD/HD group compared to controls.

Table 2. BRIEF-A scores for the AD/HD and Control group.

\begin{tabular}{ccccc}
\hline BRIEF-A scores & \multirow{2}{*}{ AD/HD $\boldsymbol{n}=\mathbf{4 0}$} & Control $\boldsymbol{n = 4 0}$ & \multicolumn{2}{c}{ Statistics } \\
\cline { 4 - 5 } & & & $t$ & $p$ \\
Inhibit & $16.28 \pm 2.75$ & $10.50 \pm 1.83$ & 11.078 & $0.000^{* * *}$ \\
Shift & $12.68 \pm 2.67$ & $8.43 \pm 1.81$ & 8.325 & $0.000^{* * *}$ \\
Emotional control & $19.43 \pm 4.96$ & $12.65 \pm 3.50$ & 7.054 & $0.000^{* * *}$ \\
Self-monitor & $11.03 \pm 2.90$ & $7.50 \pm 1.54$ & 6.802 & $0.000^{* * *}$ \\
Initiate & $18.10 \pm 3.23$ & $11.43 \pm 2.35$ & 10.559 & $0.000^{* * *}$ \\
Working memory & $19.23 \pm 3.09$ & $11.28 \pm 2.68$ & 12.288 & $0.000^{* * *}$ \\
Task-monitor & $14.25 \pm 2.23$ & $8.65 \pm 1.61$ & 12.886 & $0.000^{* * *}$ \\
Plan/Organize & $22.30 \pm 4.65$ & $13.65 \pm 2.42$ & 10.427 & $0.000^{* * *}$ \\
Organization of materials & $18.38 \pm 3.74$ & $10.95 \pm 3.05$ & 9.736 & $0.000^{* * *}$ \\
\hline BRI & $50.57 \pm 10.39$ & $32.70 \pm 7.58$ & 8.791 & $0.000^{* * *}$ \\
MI & $101.07 \pm 15.32$ & $61.95 \pm 10.30$ & 13.404 & $0.000^{* * *}$ \\
GEC & $151.65 \pm 20.63$ & $94.65 \pm 15.75$ & 13.888 & $0.000^{* * *}$ \\
\hline
\end{tabular}

Note: BRIEF-A: Behavior Rating Inventory of Executive Function, Adult Version; BRI: Behavior Regulation Index; MI: Metacognition Index; GEC: Global Executive Composite. *** $p<0.001$

\subsection{EEG data}

The AD/HD group showed a global increase in total power (Group main effect: $\mathrm{F}=$ 8.404, $p=0.005)$ compared to the control group.

Globally, the AD/HD group had significantly higher relative theta power (Group main effect: $\mathrm{F}=4.637, p=0.034$ ) than the control group. There appears to be a global decrease in relative alpha in the AD/HD group (Group main effect: $\mathrm{F}=5.228, p=0.025$ ) than the control group. In relative beta, the AD/HD group had higher power at the central regions than the control group (Group by region: $\mathrm{F}=4.480, p=0.013$ ), and group differences in the comparison of the two hemispheres were greater in the central than frontal and posterior regions (Group by region by hemisphere: $\mathrm{F}=3.021, p=0.018$ ). This indicated that the $\mathrm{AD} / \mathrm{HD}$ group had higher relative beta power in the bilateral central regions $(20.12 \%)$ compared to the control group (14.42\%). No significant group differences were found in relative delta (see Fig. 1 and Fig. 2). 

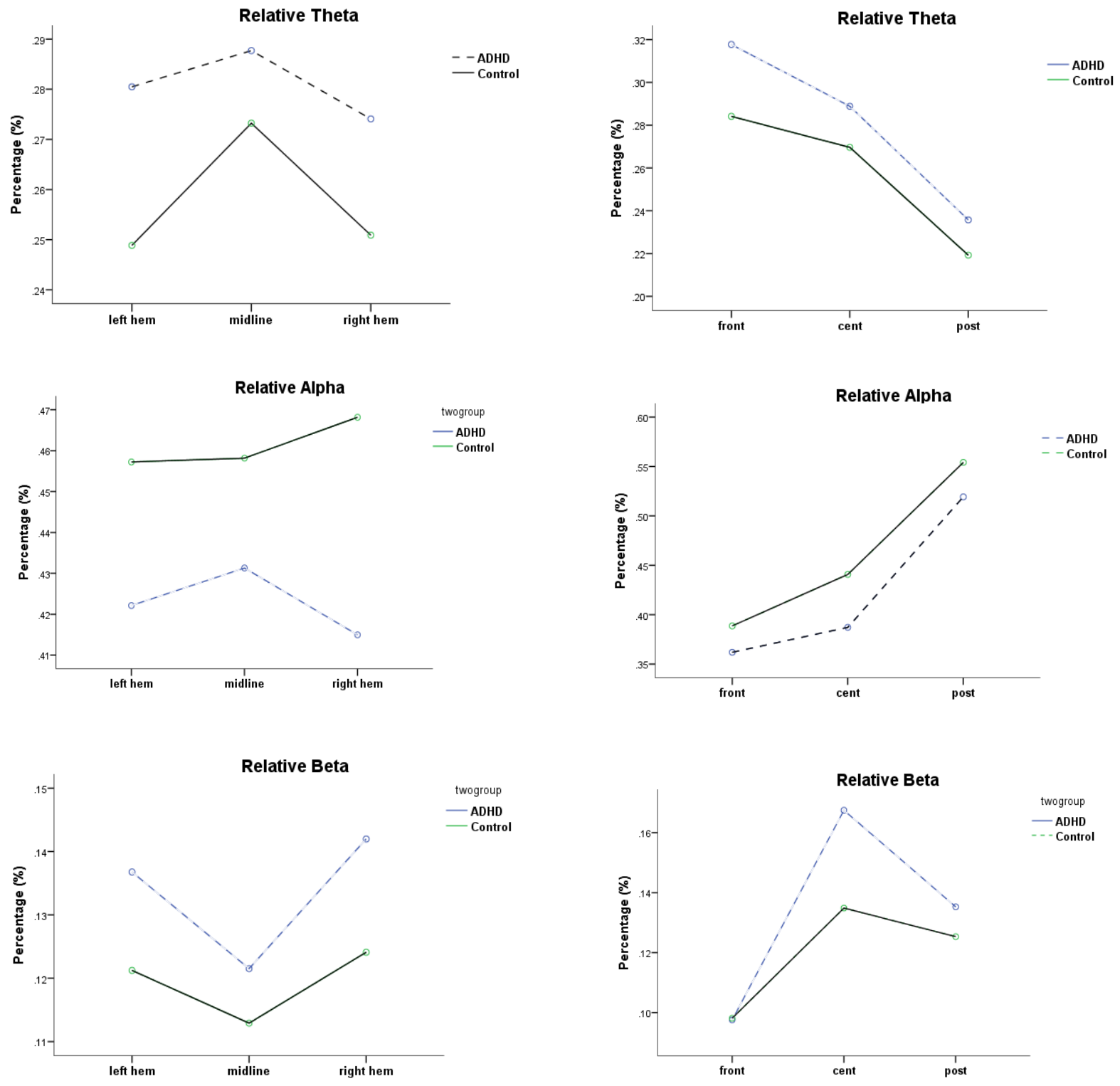
Fig. 1. Relative theta, alpha and beta power as a function of scalp region for the AD/HD group and Control group

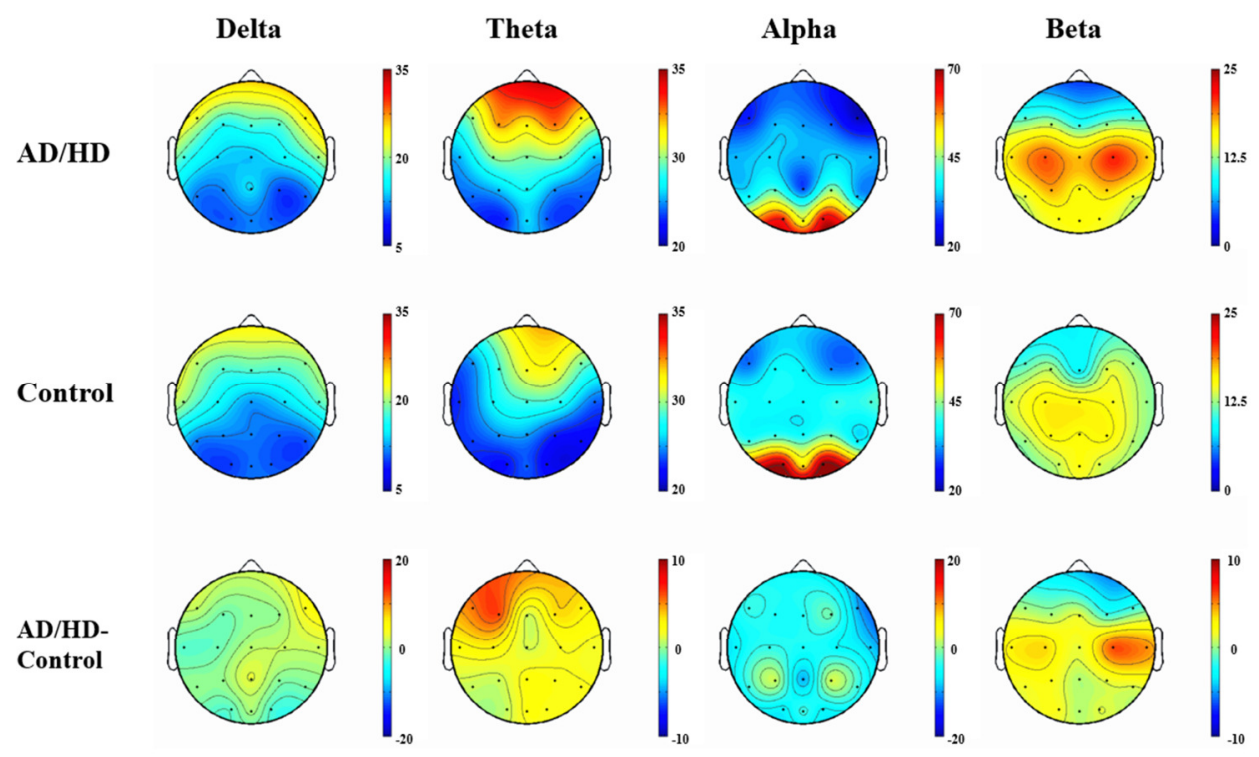

Fig. 2. Topographic maps for relative power (\%) in the AD/HD group and Control group.

\subsection{Correlations between EF and EEG}


As displayed in Fig. 3, the relative beta power in central region positively correlated with Emotional control scores for AD/HD group $(\mathrm{r}=0.464, p=0.027)$, while no correlation showed in control group $(\mathrm{r}=0.129, p=3.852)$.

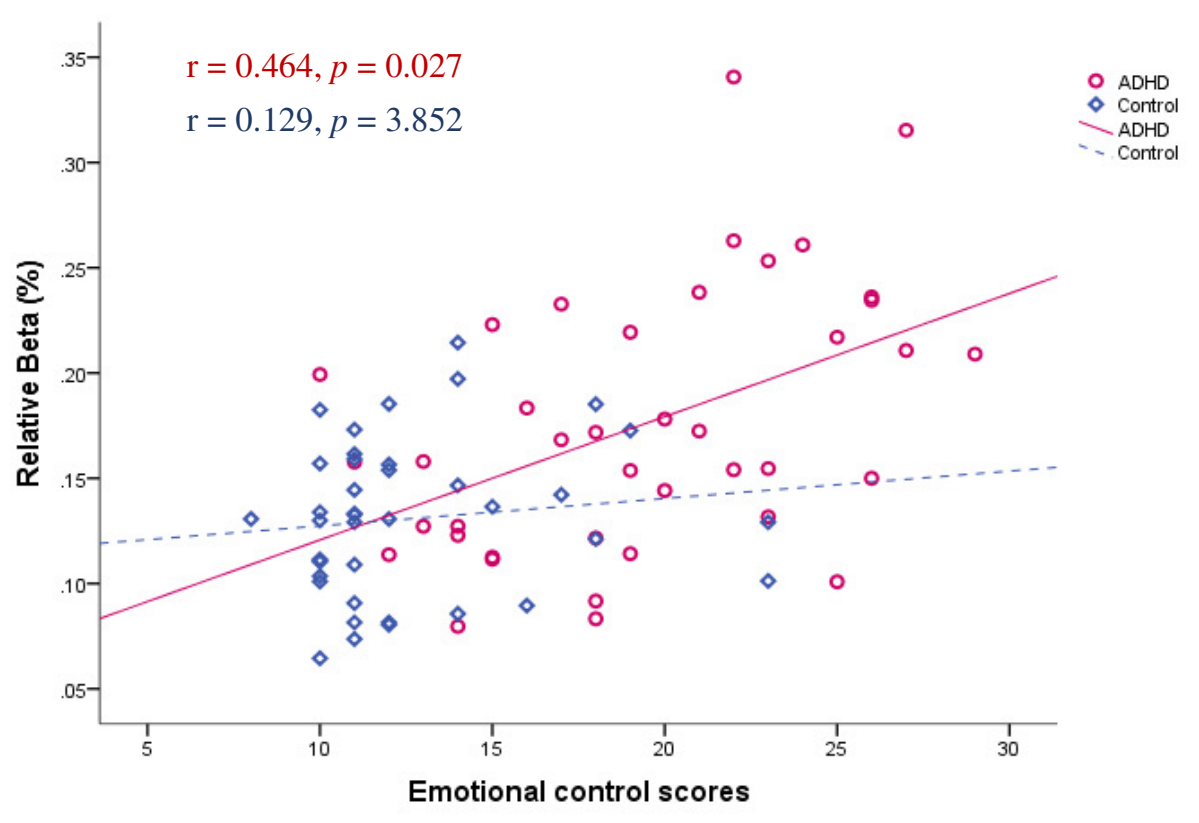

Fig. 3. Correlations between Emotional control scores and central beta power in the AD/HD group and Control group.

\section{Discussion}

To our knowledge, this is the first study on the correlation between the ecological EF deficits and abnormal resting-state EEG in AD/HD adults with high IQ. There are three key findings confirming our predictions. First, the AD/HD adults with high IQ suffered significant ecological EF deficits compared to the healthy adults. Second, the adults with AD/HD showed aberrant EEG pattern, including increased global theta, decreased global alpha and increased central beta. Third, the higher central beta activity related to the emotional control impairments in $\mathrm{AD} / \mathrm{HD}$ patients. These findings suggest that the abnormalities in resting-state EEG might involve the neuropathology of daily emotional control impairments in AD/HD adults with high IQ.

In this study, the $\mathrm{AD} / \mathrm{HD}$ group showed higher BRI and $\mathrm{MI}$ in BRIEF-A, reflecting significant impairments in maintaining control over behaviour and emotional responses, 
and difficulties in solving problems through working memory, planning, and organization during their daily life. The results consist with previous studies on adults (Biederman et al., 2011) and children with AD/HD (McCandless et al., 2007), which reported that the AD/HD individuals suffered obvious deficiencies of ecological EF. Brown et al. (2009) applied ecological EF rating scales (Brown ADD Scales, BADDS) to investigate the daily performance of activation, focus, effort, emotion and memory in high IQ adults with $\mathrm{AD} / \mathrm{HD}(\mathrm{IQ} \geqslant 120)$. This study found that percentage of $\mathrm{AD} / \mathrm{HD}$ adults impaired was significantly higher than the percentage impaired in standardization samples for ecological EF measures. These results together with this present study suggest the $\mathrm{AD} / \mathrm{HD}$ adults with high IQ suffer from similar EF impairments as do other individuals on the wider range of IQ. Thus, high IQ might not be a protect factor for AD/HD patients from having EF impairments, at least for ecological EF.

Second, this study observed aberrant resting-state EEG pattern, specifically, the globally increased theta and decreased alpha, and increased central beta in the AD/HD group. Previous researches have reported increased theta power in adults with AD/HD (Bresnahan \& Barry, 2002; Hermens et al., 2004; Koehler et al., 2009). Consistently, the present study observed significantly higher theta power in AD/HD group than controls. This pattern of excessive slow wave activity in AD/HD was suggested to reflect a decrease in dopamine function, which is related to an increase in impulsivity (Bresnahan et al., 1999). But later study failed to confirm this suggestion, instead, they found a positive correlation between theta activity and inattention symptoms in adults with AD/HD (Hermens et al., 2004). In children with AD/HD, a correlation between BRIEF scales and theta activities showed significant correlations with deficient metacognition (positively) and inhibition (negatively) (Ogrim et al., 2012). However, we did not find the relationship between theta power and BRIEF-A ratings. This discrepancy could be due to differences in subjects selections ("children" vs. "adults"). Since the theta activity will significantly decrease from childhood to adulthood in typically developing individuals, the higher theta power in adults with AD/HD might involve different neural mechanism. In healthy adults, theta activity has been suggested to play a role in subserving the transfer of information from one brain region to another during sensory information 
processing (Colgin, 2013). Also, the frontal theta activity has been observed facilitating executive functions by regulating other brain regions via inhibition (Huster et al., 2013). Accordingly, the globally increased theta activity in AD/HD adults in our study might reflect abnormal information transferring or aberrant cortical inhibition.

Our findings are consistent with some studies on $\mathrm{AD} / \mathrm{HD}$ adults finding decreased power in alpha band (Woltering et al., 2012; Poil et al., 2014). But there are discrepancies with other studies, in particular results reporting increased alpha activity (Koehler et al., 2009; Clarke et al., 2008). It has been suggested the discrepancies might due to the nature of different sample, which could explain the fact that decreased alpha power presented in the relatively high-functioning college students with AD/HD (Woltering et al., 2012). Our study also found decreased alpha power in the high-functioning (IQ $\geqslant 120)$ adults with $\mathrm{AD} / \mathrm{HD}$, emphasizing the characteristics of alpha activity in these sample. From a neurophysiological perspective, the alpha activity provides pulsed inhibition reducing the processing capabilities of a given area (Jensen \& Mazaheri, 2010). The increase in alpha activity has been considered indicative of reduced cortical activity and the decreased alpha activity in $\mathrm{AD} / \mathrm{HD}$ might related to lower inhibition of task-irrelevant brain areas (Palva \& Palva, 2007; Pfurtscheller, 2001). Combining our results of increased theta in $\mathrm{AD} / \mathrm{HD}$ adults, this resting-state EEG pattern of globally decreased alpha might link to wide-spread cortical inhibition deficits. On the basis of neurophysiological studies, slower oscillations (e.g., theta) could support functional coupling of neurons over much longer distances than fast oscillations (e.g., beta) (Buzsáki et al., 2004). Accordingly, the increased theta and decreased alpha in the whole globe might reflect abnormal integration of a large-scale brain function, which may be related to their AD/HD symptomatology and difficulties in managing complicated tasks in daily life.

Notably, we found increased beta activity in the central region and their correlations with emotional control in BRIEF-A in the AD/HD group. Excessive beta activity has been largely reported in AD/HD children and adults (Clarke et al. 2001; Poil et al., 2014). But other studies failed to observe ADHD-control differences in beta activity (Bresnahan et al. 2006), even less beta power in ADHD adults (Koehler et al., 2009). The inconsistent findings across researches may be caused by the heterogeneity of AD/HD 
patients. Previous studies linked the excess beta activity to the hyperarousal level (Clarke et al., 2011), but few study reported the relationship between beta activity and emotional control in $\mathrm{AD} / \mathrm{HD}$ adults. $\mathrm{AD} / \mathrm{HD}$ patients frequently accompany deficits in emotional self-regulation (Barkley \& Fischer, 2010; Sobanski et al., 2010), such as emotional instability, frustration intolerance, rapid and drastic changes in mood, emotional fragility, and unpredictable and explosive temper outbursts (Surman et al., 2015). And the risks of emotional dysregulation were highlighted as the most impairing aspects of $\mathrm{AD} / \mathrm{HD}$, predicting poor occupational, social, and financial adult outcomes (Barkley \& Fischer, 2010). In the present study, the $\mathrm{AD} / \mathrm{HD}$ patients with higher central beta activity showed more emotional control problems in their daily life, providing the evidence that beta activity in the central region might involve in the neuropathology of emotional control in AD/HD adults with high IQ.

For normal adults, beta activity is reported to reflect emotional and cognitive processes (Ray \& Cole, 1985) and increased beta activity is thought to result in an abnormal persistence of the status quo of brain function and a deterioration of flexible behavioral and cognitive control (Engel \& Fries, 2010). Several studies have provided indirect evidence of the relationship between excessive beta activity and impaired emotional control in $\mathrm{AD} / \mathrm{HD}$. $\mathrm{AD} / \mathrm{HD}$ adults with dysfunctional anger and emotional dysregulation have higher beta activity than controls (Jaworska et al., 2013). And delinquents with $\mathrm{AD} / \mathrm{HD}$ showed higher beta power at frontal, central, and parietal brain regions than non-delinquents with AD/HD symptoms (Meier et al., 2014). Therefore, excessive beta power was suggested to represent a risk factor for delinquent behavior in adults with AD/HD symptomatology. Then it is not unexpected that higher beta power in $\mathrm{AD} / \mathrm{HD}$ adults is relevant to the deficient emotional control, which might consequently lead to impulsive, even delinquent, behaviours.

In the diagnosis criteria of ADHD in DSM-III and DSM-IV, the emotional dysregulation related symptoms were regarded as the accompany symptoms (Shaw et al., 2014), but recently some researchers suggested to add the emotional labiality to the diagnosis criteria of AD/HD in DSM-V (Marchant et al., 2013; Skirrow \& Asherson, 2013). The investigation of the ability of emotion regulation is important for AD/HD 
patients. Our results which linking the emotional control deficits to the increased beta power might suggest the clinical value of resting-state EEG in AD/HD. The central beta activity might be an objective indicator of emotional control ability in AD/HD adults with high IQ. Although it is difficult to draw firm conclusions from the current results, the correlation offers insights for future research in linking resting-state EEG abnormalities with daily behavioral impairments.

\section{Limitation}

While the sample size was reasonable when compared to previous work, it was still small and constrained our ability to investigate the effects of comorbidities. Another confounding factor could be that there existed subtype differences regarding EEG activity in AD/HD adults. We examined mostly AD/HD-I subjects (29 ADHD-I; 2 AD/HD-H; 9 ADHD-C), whereas previous studies with adult AD/HD subjects conducted up to now mainly included AD/HD-C subtype. This complicates the direct comparison of our results with other studies. Furthermore, the relatively high intelligence scores of our $\mathrm{AD} / \mathrm{HD}$ sample compared to previous studies may confound the comparability of our findings to others and consequently impede generalizability of the results. 


\section{Reference}

American Psychiatric Association. (2013). Diagnostic and statistical manual of mental disorders, 5th edn, Arlington, VA: American Psychiatric Publishing.

Barkley, R. A. (1997). Behavioral inhibition, sustained attention, and executive functions: constructing a unifying theory of ADHD. Psychol Bull, 121(1), 65-94.

Barkley, R. A., \& Fischer, M. (2010). The unique contribution of emotional impulsiveness to impairment in major life activities in hyperactive children as adults. Journal of the American Academy of Child \& Adolescent Psychiatry, 49, 503-513.

Barkley, R. A., \& Murphy, K. R. (2011). The Nature of Executive Function (EF) Deficits in Daily Life Activities in Adults with ADHD and Their Relationship to Performance on EF Tests. Journal of Psychopathology and Behavioral Assessment, 33(2), 137-158. doi: 10.1007/s10862-011-9217-x

Barry, R. J., Clarke, A. R., \& Johnstone, S. J. (2003). A review of electrophysiology inattention-deficit/hyperactivity disorder: I. Qualitative and quantitative electroencephalography. Clinical Neurophysiology, 114(2), 171-183. doi: 10.1016/S1388-2457(02)00362-0

Biederman, J., Faraone, S. V., Monuteaux, M. C., Bober, M., \& Cadogen, E. (2004). Gender effects on attention-deficit/hyperactivity disorder in adults, revisited. Biol Psychiatry, 55(7), 692-700. doi: 10.1016/j.biopsych.2003.12.003

Biederman, J., Petty, C. R., Evans, M., Small, J., \& Faraone, S. V. (2010). How persistent is ADHD? A controlled 10-year follow-up study of boys with ADHD. Psychiatry Res, 177(3), 299-304. doi: 10.1016/j.psychres.2009.12.010 
Biederman, J., Mick, E., Fried, R., Wilner, N., Spencer, T. J., Faraone, S. V. (2011). Are stimulants effective in the treatment of executive function deficits? Results from a randomized double blind study of OROS-methylphenidate in adults with ADHD. European neuropsychopharmacology, 21(7), 508-515. doi: 10.1016/j.euroneuro.2010.11.005

Boonstra, A. M., Oosterlaan, J., Sergeant, J. A., \& Buitelaar, J. K. (2005). Executive functioning in adult ADHD: a meta-analytic review. Psychol Med, 35(8), 1097-1108.

Bresnahan, S. M., Anderson, J. W., \& Barry, R. J. (1999). Age-related changes in quantitative EEG in attention-deficit/hyperactivity disorder. Biol Psychiatry, 46(12), 1690-1697. doi: 10.1016/S0006-3223(99)00042-6

Bresnahan, S. M., \& Barry, R. J. (2002). Specificity of quantitative EEG analysis in adults with attention deficit hyperactivity disorder. Psychiatry Res, 112(2), 133-144. doi: 10.1016/S0165-1781(02)00190-7

Bresnahan, S. M., Barry, R. J., Clarke, A. R., \& Johnstone, S. J. (2006). Quantitative EEG analysis in dexamphetamine-responsive adults with attention-deficit/hyperactivity disorder. Psychiatry Res, 141(2), 151-159. doi: 10.1016/j.psychres.2005.09.002

Brown, T., Reichel, P., Quinlan, D. (2009). Executive function impairments in high IQ adults with ADHD. J Atten Disord, 13(2), 8161-8167. doi: 10.1177/1087054708326113.

Buzsáki, G., Draguhn, A. (2004). Neuronal oscillations in cortical networks. Science, 304, 1926-1929.

Clarke, A. R., Barry, R. J., McCarthy, R., \& Selikowitz, M. (2001). Excess beta activity in children with attention-deficit/hyperactivity disorder: an atypical electrophysiological group. Psychiatry Res, 103(2-3), 205-218.

Clarke, A. R., Barry, R. J., Heaven, P. C., McCarthy, R., Selikowitz, M., \& Byrne, M. K. (2008). EEG in adults with attention-deficit/hyperactivity disorder. Int J Psychophysiol, 70(3), 176-183. doi: 10.1016/j.ijpsycho.2008.07.001

Clarke, A. R., Barry, R. J., Dupuy, F. E., Heckel, L. D., McCarthy, R., Selikowitz, M., \& Johnstone, S. J. (2011). Behavioural differences between EEG-defined subgroups of children with Attention-Deficit/Hyperactivity Disorder. Clinical Neurophysiology, 122(7), 1333-1341. doi: 10.1016/j.clinph.2010.12.038

Colgin, L. L. (2013). Mechanisms and functions of theta rhythms. Annu Rev Neurosci, 36, 295-312. doi: 10.1146/annurev-neuro-062012-170330

Delorme, A., \& Makeig, S. (2004). EEGLAB: an open source toolbox for analysis of single-trial EEG dynamics including independent component analysis. J Neurosci Methods, 134(1), 9-21. doi: 10.1016/j.jneumeth.2003.10.009

Engel, A. K., \& Fries, P. (2010). Beta-band oscillations--signalling the status quo? Curr Opin Neurobiol, 20(2), 156-165. doi: 10.1016/j.conb.2010.02.015

Epstein, J. N., \& Johnson, D. (2001). Conners' adult ADHD diagnostic interview for DSM-IV. New York: MHS Inc. Fuermaier, A. B., Tucha, L., Koerts, J., Aschenbrenner, S., Weisbrod, M., Lange, K. W., \& Tucha, O. (2014). Cognitive complaints of adults with attention deficit hyperactivity disorder. Clin Neuropsychol, 28(7), 1104-1122. doi: 10.1080/13854046.2014.964325

Hermens, D. F., Williams, L. M., Lazzaro, I., Whitmont, S., Melkonian, D., \& Gordon, E. (2004). Sex differences in adult ADHD: a double dissociation in brain activity and autonomic arousal. Biol Psychol, 66(3), 221-233. doi: 10.1016/j.biopsycho.2003.10.006

Hervey, A. S., Epstein, J. N., \& Curry, J. F. (2004). Neuropsychology of adults with attention-deficit/hyperactivity disorder: a meta-analytic review. Neuropsychology, 18(3), 485-503. doi: 10.1037/0894-4105.18.3.485

Huster, R. J., Enriquez-Geppert, S., Lavallee, C. F., Falkenstein, M., Herrmann, C. S. (2013). 
Electroencephalography of response inhibition tasks: functional networks and cognitive contributions. Int J Psychophysiol, 87, 217-233. doi: 10.1016/j.ijpsycho.2012.08.001

Jaworska, N., Berrigan, L., Ahmed, A. G., Gray, J., Korovessis, A., Fisher, D. J., et al. (2013). The resting electrophysiological profile in adults with ADHD and comorbid dysfunctional anger: a pilot study. Clin EEG Neurosci, 44(2), 95-104. doi: 10.1177/1550059412465607

Jensen, O., \& Mazaheri, A. (2010). Shaping functional architecture by oscillatory alpha activity: gating by inhibition. Front Hum Neurosci, 4, 186. doi: 10.3389/fnhum.2010.00186

Klassen, L. J., Katzman, M. A., \& Chokka, P. (2010). Adult ADHD and its comorbidities, with a focus on bipolar disorder. J Affect Disord, 124(1-2), 1-8. doi: 10.1016/j.jad.2009.06.036

Koehler, S., Lauer, P., Schreppel, T., Jacob, C., Heine, M., Boreatti-Hummer, A., et al. (2009). Increased EEG power density in alpha and theta bands in adult ADHD patients. J Neural Transm (Vienna), 116(1), 97-104. doi: 10.1007/s00702-008-0157-x

Lara, C., Fayyad, J., de Graaf, R., Kessler, R. C., Aguilar-Gaxiola, S., Angermeyer, M., et al. (2009). Childhood predictors of adult attention-deficit/hyperactivity disorder: results from the World Health Organization World Mental Health Survey Initiative. Biol Psychiatry, 65(1), 46-54. doi: 10.1016/j.biopsych.2008.10.005

Marchant, B. K., Reimherr, F. W., Robison, D., Robison, R. J., Wender, P. H. (2013). Psychometric properties of the Wender-Reimherr Adult Attention Deficit Disorder Scale. Psychological assessment, 25, 942-950. doi: $10.1037 / \mathrm{a} 0032797$

McCandless, S. and L, O. L. (2007). The Clinical Utility of the Behavior Rating Inventory of Executive Function (BRIEF) in the diagnosis of ADHD. Journal of attention disorders, 10, 381-389. doi: $10.1177 / 1087054706292115$

Meier, N. M., Perrig, W., \& Koenig, T. (2014). Is excessive electroencephalography beta activity associated with delinquent behavior in men with attention-deficit hyperactivity disorder symptomatology? Neuropsychobiology, 70(4), 210-219. doi: 10.1159/000366487

Ogrim, G., Kropotov, J., \& Hestad, K. (2012). The quantitative EEG theta/beta ratio in attention deficit/hyperactivity disorder and normal controls: sensitivity, specificity, and behavioral correlates. Psychiatry Res, 198(3), 482-488. doi: 10.1016/j.psychres.2011.12.041

Palva, S., \& Palva, J. M. (2007). New vistas for alpha-frequency band oscillations. Trends Neurosci, 30(4), 150-158. doi: 10.1016/j.tins.2007.02.001

Pfurtscheller, G. (2001). Functional brain imaging based on ERD/ERS. Vision Res, 41(10-11), 1257-1260. doi: 10.1016/S0042-6989(00)00235-2

Poil, S. S., Bollmann, S., Ghisleni, C., O'Gorman, R. L., Klaver, P., Ball, J., et al. (2014). Age dependent electroencephalographic changes in attention-deficit/hyperactivity disorder (ADHD). Clin Neurophysiol, 125(8), 1626-1638. doi: 10.1016/j.clinph.2013.12.118

Ray, W. J., \& Cole, H. W. (1985). EEG alpha activity reflects attentional demands, and beta activity reflects emotional and cognitive processes. Science, 228(4700), 750-752.

Roth, R. M., Isquith, P. K., \& Gioia, G. A. (2005). BRIEF-A: Behavior Rating Inventory of Executive Function Adult Version: Professional Manual. Lutz, FL: Psychological Assessment Resources.

Salomone, S., Fleming, G. R., Bramham, J., O'Connell, R. G., \& Robertson, I. H. (2016). Neuropsychological Deficits in Adult ADHD: Evidence for Differential Attentional Impairments, Deficient Executive Functions, and High Self-Reported Functional Impairments. J Atten Disord. doi: $10.1177 / 1087054715623045$

Shaw, P., Stringaris, A., Nigg, J., \& Leibenluft, E. (2014). Emotion dysregulation in attention deficit hyperactivity 
disorder. The American Journal of Psychiatry, 171, 276-293. doi: 10.1176/appi.ajp.2013.13070966

Skirrow, C., McLoughlin, G., Kuntsi, J., Asherson, P. (2009). Behavioral, neurocognitive and treatment overlap between attention-deficit/hyperactivity disorder and mood instability. Expert review of neurotherapeutics, 9, 489-503. doi: 10.1586/ern.09.2

Sobanski, E., Banaschewski, T., Asherson, P., Buitelaar, J., Chen, W., Franke, B., . . Faraone, S. V. (2010). Emotional lability in children and adolescents with attention deficit/hyperactivity disorder (ADHD): Clinical correlates and familial prevalence. Journal of Child Psychology and Psychiatry, 51, 915-923. doi: 10.1111/j.1469-7610.2010.02217.x

Stavro G. M., Ettenhofer M. L., Nigg J. T. (2007). Executive functions and adaptive functioning in young adult attention-deficit/hyperactivity disorder. J Int Neuropsychol Soc, 13(2), 324-334. doi: $10.1017 / \mathrm{S} 1355617707070348$

Surman, C. B., Biederman, J., Spencer, T., Miller, C. A., Petty, C. R., \& Faraone, S. V. (2015). Neuropsychological deficits are not predictive of deficient emotional self-regulation in adults with ADHD. Journal of Attention Disorders, 19, 1046-1053. doi: 10.1177/1087054713476548

van Dongen-Boomsma, M., Lansbergen, M. M., Bekker, E. M., Kooij, J. J., van der Molen, M., Kenemans, J. L., \& Buitelaar, J. K. (2010). Relation between resting EEG to cognitive performance and clinical symptoms in adults with attention-deficit/hyperactivity disorder. Neurosci Lett, 469(1), 102-106. doi: 10.1016/j.neulet.2009.11.053

Vynorius, K. C., Paquin, A. M., \& Seichepine, D. R. (2016). Lifetime Multiple Mild Traumatic Brain Injuries Are Associated with Cognitive and Mood Symptoms in Young Healthy College Students. Front Neurol, 7, 188. doi: 10.3389/fneur.2016.00188

Willcutt, E. G., Doyle, A. E., Nigg, J. T., Faraone, S. V., \& Pennington, B. F. (2005). Validity of the executive function theory of attention-deficit/hyperactivity disorder: a meta-analytic review. Biol Psychiatry, 57 (11), 1336-1346. doi: 10.1016/j.biopsych.2005.02.006

Woltering, S., Jung, J., Liu, Z., \& Tannock, R. (2012). Resting state EEG oscillatory power differences in ADHD college students and their peers. Behav Brain Funct, 8, 60. doi: 10.1186/1744-9081-8-60 